Article

\title{
Calliblepharis jubata Cultivation Potential-A Comparative Study between Controlled and Semi-Controlled Aquaculture
}

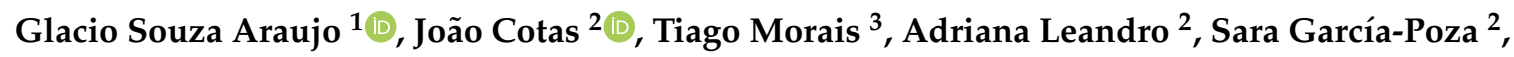 \\ Ana M. M. Gonçalves ${ }^{2,4}$ and Leonel Pereira ${ }^{2, *(D)}$ \\ 1 Ceará Federal Institute/IFCE-Campus Aracati, Aracati 62800-000, Brazil; glacio@ifce.edu.br \\ 2 Department of Life Sciences, MARE-Marine and Environmental Sciences Centre, University of Coimbra, \\ 3001-456 Coimbra, Portugal; jcotas@gmail.com (J.C.); adriana.leandro@uc.pt (A.L.); \\ sara.g.poza@uc.pt (S.G.-P.); amgoncalves@uc.pt (A.M.M.G.) \\ 3 Lusalgae, Lda., Incubadora de Empresas da Figueira da Foz, Rua das Acácias N ${ }^{\circ}$ 40-A, \\ 3090-380 Figueira da Foz, Portugal; tsmorais@lusalgae.pt \\ 4 Department of Biology and CESAM, University of Aveiro, 3810-193 Aveiro, Portugal \\ * Correspondence: leonel.pereira@uc.pt
}

Received: 29 September 2020; Accepted: 20 October 2020; Published: 27 October 2020

check for updates

\begin{abstract}
Calliblepharis jubata is an edible red seaweed and a carrageenan primary producer, considered native in Figueira da Foz (Portugal). C. jubata has the particularity of producing only one kind of carrageenan, the iota fraction. However, this seaweed is not yet valuable for the food industry or even for human consumption. In this work, we characterize important biochemical compounds of C. jubata growing up within different cultivation techniques and wild specimens. The aim of this work is to know if there are differences between the biological compounds of interest and identify the advantages for human consumption and the food industry. The results supported the nutritional value of the seaweed, where the ones from inshore cultivation $(\mathrm{T})$ were more identical to the wild specimens $(\mathrm{F})$, than the indoor C. jubata $(\mathrm{A}, \mathrm{B}, \mathrm{C})$. The parameters analyzed were fatty acids, carbohydrates and carrageenan content.
\end{abstract}

Keywords: Calliblepharis jubata; aquaculture; fatty acids; carbohydrates; carrageenan

\section{Introduction}

Several eastern countries traditionally consume seaweed as food, mainly Japan, China and Korea [1], due to its high nutritional value as a source of proteins, carbohydrates, vitamins and minerals [2,3]. The great economic interest is also justified by the growing demand for phycocolloid for different uses in the pharmaceutical, food and cosmetics industries [4-9], which has led several countries to cultivate seaweed [10]. The main hydrocolloids of commercial interest in marine algae (agar, carrageenan and alginate) are also known to have several biological activities, such as anticoagulant [11], antithrombotic [12], antiviral [13], immunostimulants [14], thus having great biotechnological applicability [15]. The variety of seaweed commercial applications discussed raises an important sustainable question, which cannot be taken lightly further. In order to sustain a steady supply, a solution that allows a minimal interaction with marine ecosystems is needed. Aquaculture can be that solution $[16,17]$. Food safety can only be achieved with a feasible and controllable food source. The seaweed aquaculture is considered to be one of the major hypothesis to be part of the solution to obtain global food security [5]. However to be part of the solution, the potential of seaweeds needs to be characterized and, then selected the seaweeds that are simple to be cultivated, without major 
problems. And also, the selected seaweeds need to have a good nutritional value as demonstrated by Leandro et al. [5].

Seaweed aquaculture is, above all, a production method which can be scaled up to very high proportions, maintaining several advantages $[16,18]$. Thus, aquaculture technologies are considered a sustainable alternative to optimizing outputs (quantity and quality) and reducing costs and pollution. These technologies and methods need to be adapted to the environmental request from the aquaculture location and species cultivated, because the aquaculture can be offshore or onshore and abiotic and biotic factors that influence the aquaculture system are very different, which will have a high influence in the aquaculture productivity [19].

Inland saline aquaculture is defined as land-based aquaculture using saline or saltpans groundwater. Inland saline water can differ in chemistry compared with coastal seawater and adjusting the chemistry or choosing species that are tolerant to the differences is one of the major challenges for expansion of inland saline aquaculture. For seaweed aquaculture, a sure water supply and disposal through terminal evaporation ponds provide critical and expensive infrastructure [20]. Therefore, inland saline aquaculture encompasses a number of culture species, systems and water types. The potential for expansion of these production systems is almost unlimited. With the increasing demands on potable water and marine coastal locations, use (or re-use) of inland saline waters provides a critical resource for high-quality seafood production using unproductive or even detrimental, resources. Integration of seaweed aquaculture in conventional fish farms, halophytic culture, would further increase the efficiency and sustainability of these food production systems [20].

All in all, basic and applied research into practical management systems for these systems is rapidly providing us with the knowledge of how to turn these into profitable farming ventures and novel food production methods are needed to further improve global wellbeing and inland saline aquaculture is bound to be a most valuable tool [20].

The future development work of aquaculture techniques, both in shore and off shore, has to account for studies into those subjects and relate those with designs prepared for strong water movement and rich inorganic nutrient concentrations in order to enhance nutrient uptake (off shore aquaculture) or with aeration, dividers for agitation and $\mathrm{CO}_{2}$ adjustments for $\mathrm{pH}$ control (in shore aquaculture).

The benthic seaweed Calliblepharis jubata [21] (Figure 1), which belongs to Class Rhodophyta, Order Gigartinales and Family Cystocloniaceae, is a candidate with an interesting profile for cultivation and extraction of phycocolloids. It presents a dark reddish-brown, cartilaginous but flaccid stem, up to $30 \mathrm{~cm}$ in length. Stipe \pm cylindrical, up to $10 \mathrm{~cm}$ in length; slightly branched rhizoid. Lanceolate blade, up to $15 \mathrm{~cm}$ wide, simple, irregularly pinned or dichotomously divided, coated by rolled or hook-shaped proliferations, similar to tendons up to $10 \mathrm{~cm}$ or more; blade surface with small spiny growths in well-developed specimens. They have rocks as habitat or are epiphyte, from the medium horizon of the intertidal level to the shallow infralittoral [22].

The studies in this seaweed are mainly about their polysaccharide content. Zinoun et al. [23] reported sulfohydrolase catalyze reaction in this species, which converts carrageenan precursors molecules ( $\mu$ - and $\nu$-carrabiose) into 3,6 anhydrogalactose derivatives modifying the non-gelling precursors characteristic into gelling carrageenans derivatives, such iota-carrageenan [24]. Deslandes et al. [25] recurred to spectroscopic techniques to elucidate about the monosacharides composition of four red seaweeds, which demonstrated that the main precursor of carrageenan in C. jubata is the $v$-carrabiose. This seaweed carrageenan has been characterized by vibrational spectroscopy (FTIR-Raman and FITR-ATR), that gives a hybrid iota or iota-kappa carrageenan, with very low content of kappa-carrageenan, in the all C. jubata life cycle phase [26]. 


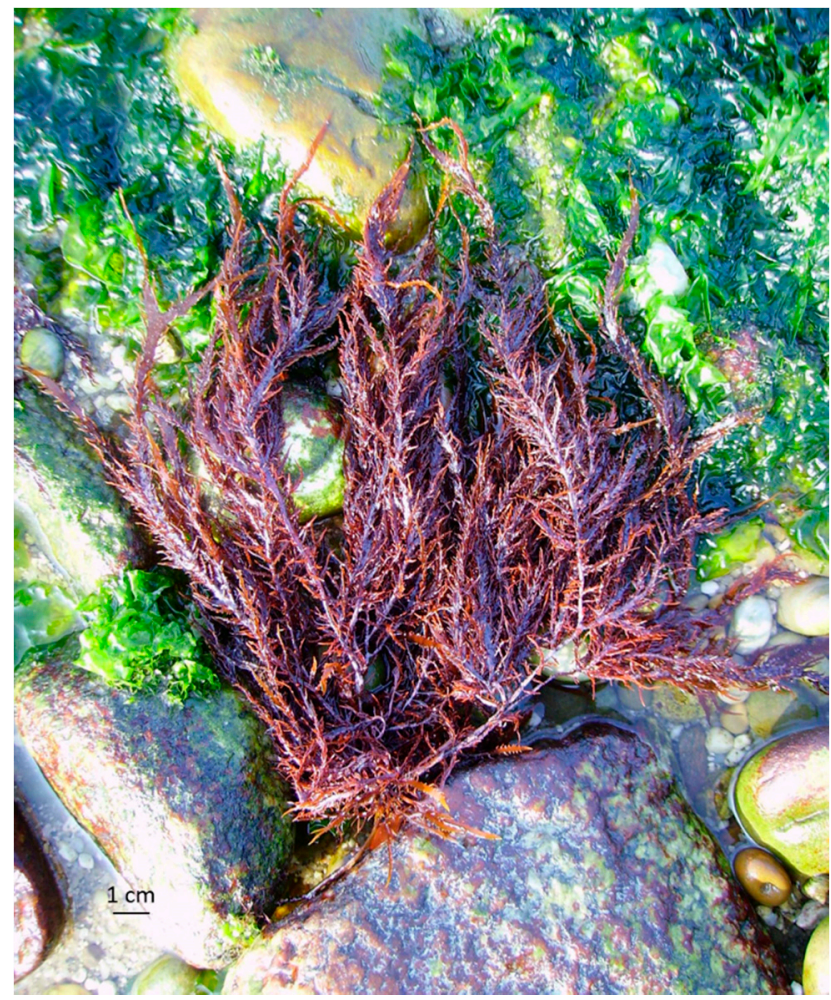

Figure 1. Calliblepharis jubata.

Thus, C. jubata is an iota-carrageenan primary producer and is considered native in Figueira da Foz (Coimbra, Portugal). However, this seaweed is not yet valuable for the food industry or even for human consumption [27].

In this work, we characterize important biochemical compounds (fatty acids, carbohydrates) and yield of an important compound (carrageenan) in wild specimens of $C$. jubat $a$ and, furthermore with different cultivation techniques to confirm if this species can be cultivated and be a new source of an important compound in the food industry and also, in human direct consumption. Still, there is a lack of information in literature about this species, with a single article of Zinoun and Cosson [28] supporting the possibility of $C$. jubata's cultivation.

\section{Materials and Methods}

\subsection{Reagents}

Methanol was purchased from José Manuel Gomes dos Santos, Lda., Odivelas, Portugal and acetone from the Ceamed Lda., Funchal, Portugal. Ethanol was obtained from Valente e Ribeiro. Lda., Belas, Portugal and sodium hydroxide from Sigma-Aldrich $\mathrm{GmbH}$, Steinheim, Germany.

\subsection{Seaweed Collection}

The specimens of Calliblepharis jubata were collected in Praia da Tamargueira, Buarcos, Figueira da Foz $\left(40^{\circ} 10^{\prime} 18.6^{\prime \prime} \mathrm{N}, 8^{\circ} 53^{\prime} 44.4^{\prime \prime} \mathrm{W}\right)$, Portugal (Figure 2). Sampling was conducted in May 2020 from the sites with well-established $C$. jubata patches and without epiphytes or degradation visible at eyesight. The $C$. jubata specimens were collected in two different tidal pools. The pools distance was proximate $1 \mathrm{~m}$ between them horizontally to guarantee the most identical composition and physical state between the seaweed collected for analysis and cultivation. Once harvested, samples were stored in plastic bags for transport to the laboratory, in a cool box. The samples were then transported in cold boxes to the laboratory, where they were washed with filtered seawater in order to remove sands, contaminants and other organisms that they may have had. After that, the samples were separated: 
some specimens were weighted and placed in culture systems, while the remaining biomass was rapidly washed with distilled water, cleaned with paper and stored at $-20^{\circ} \mathrm{C}$ for further analysis.

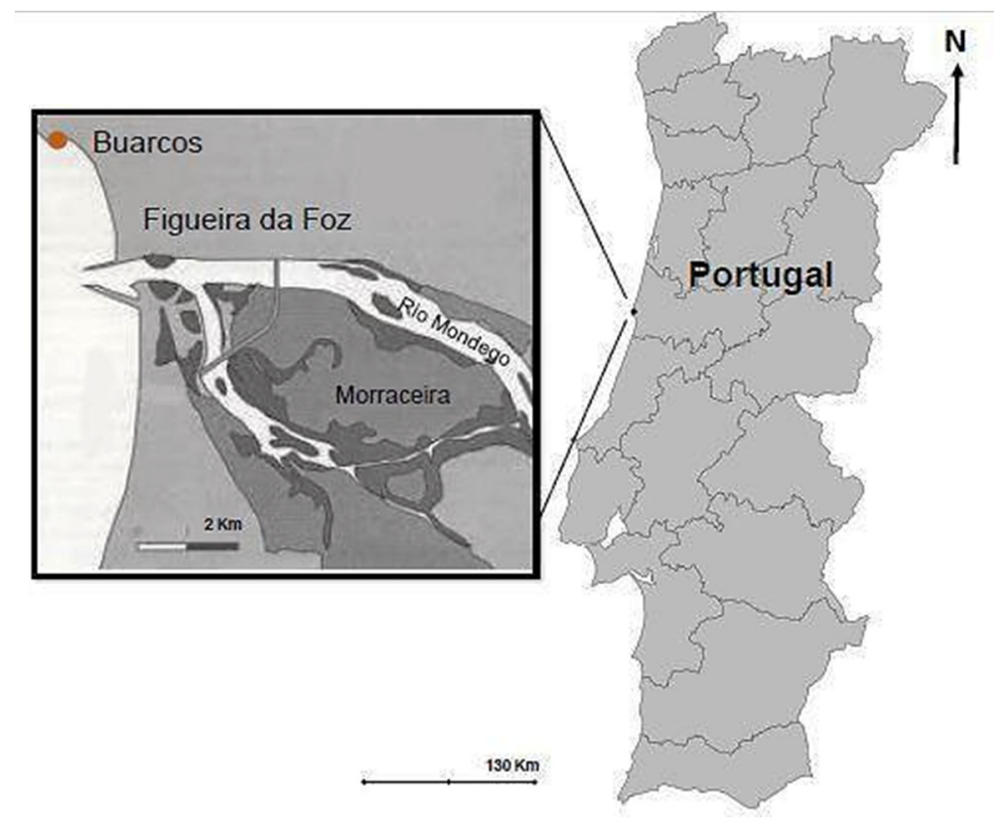

Figure 2. Sampling site: Praia da Tamargueira, Buarcos, Figueira da Foz, Coimbra, Portugal.

\subsection{Seaweed Cultivation}

Juveniles' specimens were selected during the primary seaweed collection and transported to the laboratory in plastic bags containing seawater and packed in cool boxes. Seawater was also collected to help in the specimens washing process, as well as to be the medium of the indoor cultivation first stage of the $C$. jubata, after filtering with paper filters.

\subsubsection{Indoor Cultivation}

Most of the juveniles used for cultivation $(<5 \mathrm{~cm})$ were selected for the indoor cultivation under controlled conditions at the Marine Algae Laboratory (MARE UC), Department of Life Sciences, Faculty of Science and Technology, University of Coimbra, Coimbra, Portugal.

The cultivation apparatus were round volumetric flasks of $1 \mathrm{~L}$, containing $1 \mathrm{~L}$ of filtered seawater, with artificial light and artificial aeration from a diaphragm pump, $24 \mathrm{~h}$ per day of light. The light was on during periods of $16 \mathrm{~h}$ (day period $16 \mathrm{~h}^{\mathrm{L}}: 8 \mathrm{~h}^{\mathrm{D}}$ ), the light bar was at a distance of $10 \mathrm{~cm}$ of the flasks horizontally, the light was an OSRAM light tube with $18 \mathrm{~W}, 3100 \mathrm{LM}$ and $4000 \mathrm{k}$.

The cultivation was carried out in triplicate, with average initial weights of $1.75 \mathrm{~g} \pm 0.59$ of $C$. jubata per liter of seawater, for a period of 42 days. The room temperature was $24{ }^{\circ} \mathrm{C} \pm 2{ }^{\circ} \mathrm{C}$ and $55 \% \pm 5 \%$ humidity. Every two days, the water in each container was renewed three times a week. Once a week, the algae were weighed on a semi-analytical balance to monitor their average growth.

\subsubsection{Inshore Cultivation}

In order to obtain more information, we recurred during the MENU—Marine macroalgaE-alternative recipes for a daily Nutritional diet project (Project Reference: FA_05_2017_011) to a one prototype cultivation tank from Lusalgae Lda. (Figueira da Foz, Coimbra, Portugal), to check the potential of $C$. jubata in the method applied in this seaweed aquaculture company. To obtain sufficient biomass for the extraction of compounds of biological interest and to compare them with seaweed grown under controlled conditions, in this stage, C. jubata grew in a water tank exposed to direct sunlight with aeration during the day (the aeration did not work during the night, only worked in the sunlight). 
The specimens cultivated where identical to the Indoor cultivation (collected in the same pools in the same collection date, with length lower than $5 \mathrm{~cm}$ ), to prevent the biochemical composition differential due to the seaweed growth state. With this, the cultivation method was the principal factor of differentiation of the biochemical profile.

The medium of cultivation was estuarine seawater (29\%-34\%) of the Mondego River estuary, in Figueira da Foz, Coimbra, Portugal, without adding nutrients.

The cultivation tank had a capacity of $1000 \mathrm{~L}$, containing $800 \mathrm{~L}$ of mechanically filtered estuarine water.

The cultivation started from an initial biomass of $666 \mathrm{~g}$ in a single tank. Approximately $75 \%$ of the water volume was renewed three times a week and after three weeks the entire biomass was retired to further analysis. The seaweed cultivation method was done by the Lusalgae cultivation standardized method to the red seaweeds.

\subsection{Seaweed Treatment before the Biochemical Characterization}

The specimens were washed briefly with distilled water to remove salts and dried in an air force oven (Raypa DAF-135, R. Espinar S.L., Barcelona, Spain) at $60{ }^{\circ} \mathrm{C}, 48 \mathrm{~h}$. The dried algae were finely ground with a commercial mill (Taurus aromatic, Oliana, Spain) $(\leq 1 \mathrm{~mm})$ in order to render the samples uniform and then, stored in a dark room, in a box with silica gel to reduce the humidity, at ambient temperature $\left( \pm 24^{\circ} \mathrm{C}\right)$. The dried biomass was stored to protect it from the light, until the analysis proceeds.

\subsubsection{Fatty Acids Characterization}

Samples were divided into three replicates and were processed in order to obtain the extracts. The lipids were extracted and methylated to fatty acids methyl esters (FAMEs) following the methodology described in Gonçalves et al. [29]. Samples were incubated with methanol for the extraction of lipids. The internal standard nonadecanoic acid C19 (Fluka 74208) was added to each sample to quantify the fatty acid (FA). Then Sodium chloride was added and the samples were centrifuged to the separation of FAMEs. Then, samples were centrifuged and stored at $-80^{\circ} \mathrm{C}$. FAMEs identification was carried out through Gas chromatography-Mass spectrometry (GC-MS), equipped with a $0.32 \mathrm{~mm}$ internal diameter, $0.25 \mu \mathrm{m}$ film thickness and $30 \mathrm{~m}$ long TR-FFAP column. The sample $(1.00 \mu \mathrm{L})$ was injected with a splitless mode. The column temperature was programmed to increase from 80 to $230^{\circ} \mathrm{C}$, with helium as the carrier gas, at a flow rate of $1.4 \mathrm{~mL} \mathrm{~min}^{-1}$. Integration of FAMEs peaks was carried out using the equipment's software. The identification of each peak was performed by retention time and mass spectrum of each FAME, comparing to the Supelco ${ }^{\circledR} 37$ component FAME mix (Sigma-Aldrich, Steinheim, Germany). Quantification of FAMEs was done as previously described in Gonçalves et al. [29].

\subsubsection{Carbohydrates Content Characterization}

The profiles of three replicates were extracted throughout a hydrolysis, followed by reduction and acetylation [30]. Samples were incubated with sulphuric acid and then added distilled water. After a reduction with ammonia and sodium borohydride, acetylation was performed with acid acetic, methylimidazole and acetic acid anhydride as described in Coimbra et al. [22]. The internal standard 2-desoxiglucose was added to the quantification of sugars. Samples were centrifuged and resuspended in acetone to be injected in the Gas-chromatography with a flame ionization detector (GC-FID). The samples were run through a Thermo Scientific Trace 1310 chromatography equipment (Waltham, MA, USA) equipped with a GC-FID. A TG-WAXMS A (30 m length, $0.32 \mathrm{~mm}$ i.d., $0.25 \mu \mathrm{m}$ film thickness) GC column was used and the oven was programmed to an initial temperature of $180^{\circ} \mathrm{C}$, following a linear temperature increase of $5{ }^{\circ} \mathrm{C} \mathrm{min}^{-1}$ until the final temperature of $230{ }^{\circ} \mathrm{C}$ was reached, maintaining this temperature for $12 \mathrm{~min}$. The carrier gas was helium at a flow rate of $2.5 \mathrm{~mL} \mathrm{~min}{ }^{-1}$. The monosaccharides were identified by retention time comparison with standards. Quantification 
of sugars was performed by comparison of the sugar chromatographic peaks to the peaks obtained for the internal standard used (2-desoxiglucose).

\subsection{Carrageenan Refined Alkali Extraction}

Alkali extraction was performed according to the method described by Pereira et al. [31]. The milled seaweed was weighted in a scale (Radwag WLC 1/A2, Radwag, Radom, Poland) and $1 \mathrm{~g}$ samples was used $(n=3)$. Before extraction, the milled seaweed material $(1 \mathrm{~g})$ was resuspended and pretreated with an acetone: methanol $(1: 1)$ solution in a final concentration of $1 \%(\mathrm{~m} / \mathrm{v})$ for $16 \mathrm{~h}$, at $4{ }^{\circ} \mathrm{C}$, to eliminate the organic-soluble fraction. The liquid solution was decanted, and the seaweed residues obtained were dried in an air force oven (Raypa DAF-135, R. Espinar S.L., Barcelona, Spain) at $60^{\circ} \mathrm{C}$ before the extraction method.

The samples were placed in $150 \mathrm{~mL}$ of $\mathrm{NaOH}(1 \mathrm{M})(1 \mathrm{~g}$ of initial seaweed: $150 \mathrm{~mL}$ of $\mathrm{NaOH}$ solution) in a hot water bath system (GFL 1003, GFL, Burgwedel, Germany), at 85-90 ${ }^{\circ} \mathrm{C}$, for $3 \mathrm{~h}$. The solutions were hot filtered, under vacuum, through a cloth filter supported in a Buchner funnel and a Kitasato flask. After that, the extracts were again filtered under vacuum with a Goosh 2 silica funnel. The extract was evaporated (rotary evaporator model: 2600000, Witeg, Germany) under vacuum to one-third of the initial volume. The carrageenan was precipitated by adding the warm solution to twice its volume of $96 \%$ ethanol. The carrageenan precipitated was washed with ethanol, $48 \mathrm{~h}$ at $4{ }^{\circ} \mathrm{C}$ before drying in an air force oven.

\subsection{Statistical Analysis}

For the characterization assays, the statistical analysis of variance (ANOVA) was performed, one for each component, followed by Tukey's tests in order to compare the values in the quantifications within the treatment (type of cultivation's tank or field samples). To determine whether any of the differences between the means were statistically significant, the $p$-value was compared to a significance level (denoted as $\alpha$ or alpha) of 0.05 . Differences were considered significant when the $p$ value was lower than 0.05 .

\section{Results}

In the two seaweeds cultivation systems, we used identical specimens, collected in the same spots in the same collection date. However, at the end of the cultivation of C. Jubata under controlled conditions (42 days), a final average weight of $4.25 \pm 1.09 \mathrm{~g}$ was obtained (Table 1 ). In the inshore aquaculture the initial biomass only grew $100 \mathrm{~g}$, performing $766 \mathrm{~g}$ after three weeks.

Table 1. Average weight of $C$. jubata macroalgae during cultivation under controlled conditions. The values indicate the average weight of the macro algae \pm standard deviation.

\begin{tabular}{cc}
\hline Days of Culture & Weight Average (g) \\
\hline 00 & $1.75 \pm 0.59$ \\
07 & $2.28 \pm 0.16$ \\
14 & $2.38 \pm 0.11$ \\
21 & $2.78 \pm 0.24$ \\
28 & $3.32 \pm 0.41$ \\
35 & $4.00 \pm 0.92$ \\
42 & $4.25 \pm 1.09$ \\
\hline
\end{tabular}

\subsection{Fatty Acids Characterization}

Field and Tank cultivated samples were richer in total fatty acids than the cultivated samples under the controlled laboratory conditions. Table 2 shows the Tank $\mathrm{T}$ was richer in saturated fatty acids (SFA, $\left.2186.69 \mu \mathrm{g} \cdot \mathrm{g}^{-1} \mathrm{dw}\right)$, while aquarium $C$ was the poorest $\left(1257.64 \mu \mathrm{g} \cdot \mathrm{g}^{-1} \mathrm{dw}\right)$. Furthermore, tank $\mathrm{T}$ was also the highest in monounsaturated fatty acids (MUFA, $305.74 \mu \mathrm{g} \cdot \mathrm{g}^{-1} \mathrm{dw}$ ) and polyunsaturated fatty 
acids (PUFA, $137.96 \mu \mathrm{g} \cdot \mathrm{g}^{-1} \mathrm{dw}$ ) concentration respectively, whereas aquarium B presented the lowest concentration on MUFA (266.03 $\left.\mu \mathrm{g} \cdot \mathrm{g}^{-1} \mathrm{dw}\right)$ and PUFA $\left(20.79 \mu \mathrm{g} \cdot \mathrm{g}^{-1} \mathrm{dw}\right)$. However, the samples of the field had the highest concentration of highly unsaturated fatty acids (HUFA, $2602.41 \mu \mathrm{g} \cdot \mathrm{g}^{-1}$ $\mathrm{dw})$ and the lowest was aquarium B $\left(506.73 \mu \mathrm{g} \cdot \mathrm{g}^{-1} \mathrm{dw}\right)$. Referring to the total fatty acid composition, field samples presented the highest value $\left(5289.05 \mu \mathrm{g} \cdot \mathrm{g}^{-1} \mathrm{dw}\right)$ while aquarium B showed the lowest (2105.43 $\mu \mathrm{g} \cdot \mathrm{g}^{-1} \mathrm{dw}$ ) content (Figure 3).
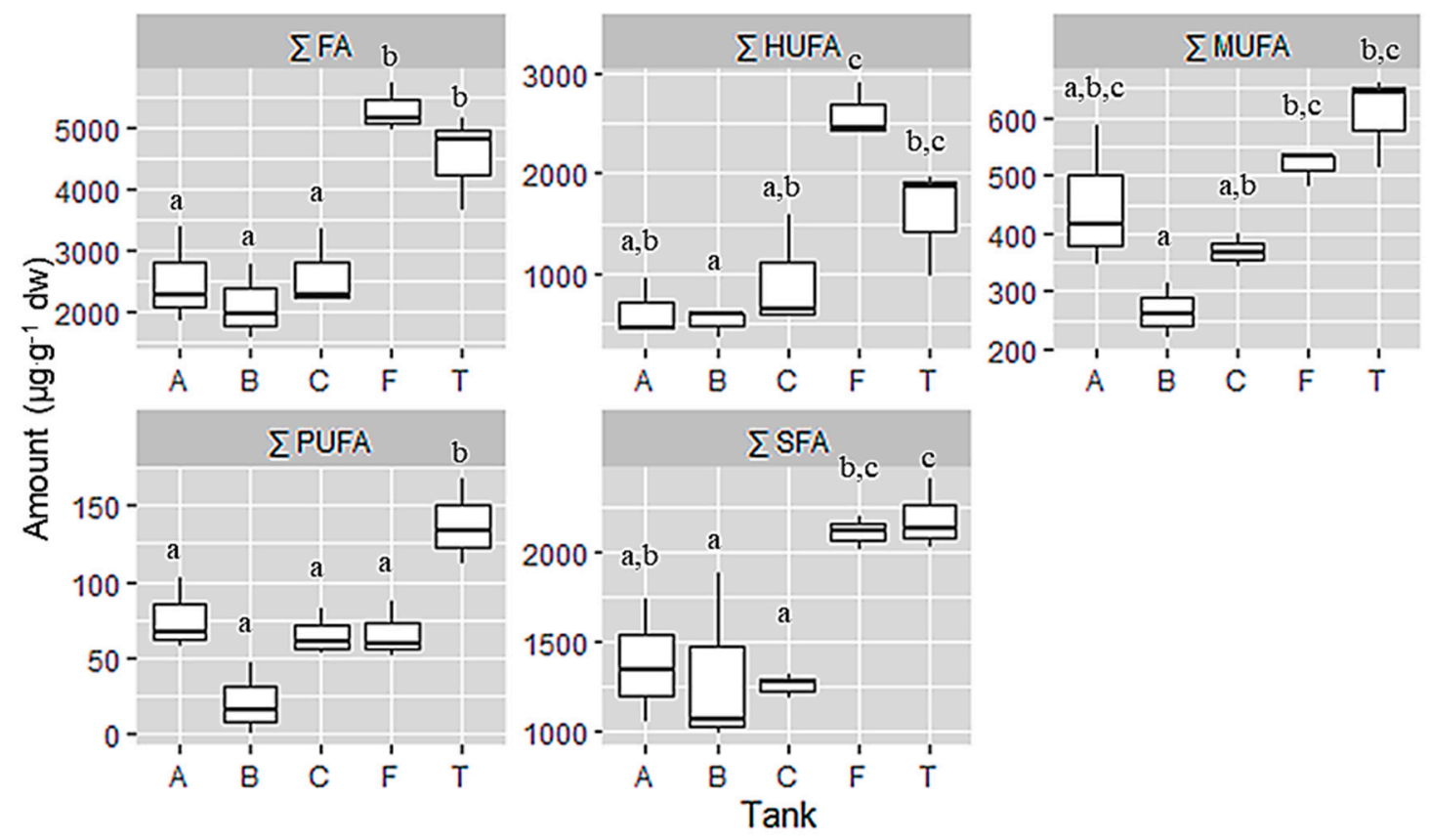

Figure 3. Sum of fatty acid group and total fatty acid expressed in $\mu \mathrm{g} \cdot \mathrm{g}^{-1} \mathrm{dw}$ from samples of $C$. jubata obtained from cultivated in indoor balloons (A, B and C), cultivated in outdoor tank (T) and collected from the field $(F)$. The same upper letters $(a, b, c)$ mean there are no differences between the treatments (cultivation type). Data as mean value, distribution and variance; $n=3$. 
Table 2. Fatty acid composition and summary of fatty acid grouped in saturated (SFA), monounsaturated (MUFA), polyunsaturated (PUFA), highly unsaturated (HUFA) and total of fatty acids (FA). Results were expressed in $\mu \mathrm{g} \cdot \mathrm{g}^{-1}$ of dry weight $(\mathrm{dw})$ from samples of $C$. jubata obtained from cultivated in indoor balloons (A, B and C), cultivated in outdoor tank (T) and collected from the field (F). Data as mean \pm SEM; $n=3$.

\begin{tabular}{cccccccccccccccc}
\hline & & A & & & B & & & C & & F & \\
\hline C14:0 & 244.83 & \pm & 34.54 & 209.08 & \pm & 51.07 & 233.02 & \pm & 11.43 & 343.22 & \pm & 9.74 & 353.59 & \pm & 20.52 \\
C16:0 & 1013.99 & \pm & 144.06 & 1055.26 & \pm & 217.31 & 964.31 & \pm & 38.88 & 1707.55 & \pm & 44.05 & 1723.46 & \pm & 100.96 \\
C18:0 & 116.05 & \pm & 24.74 & 47.53 & \pm & 15.68 & 60.31 & \pm & 6.42 & 53.99 & \pm & 4.71 & 109.64 & \pm & 9.11 \\
$\sum$ SFA & 1374.88 & \pm & 200.39 & 1311.87 & \pm & 283.84 & 1257.64 & \pm & 40.01 & 2104.76 & \pm & 54.10 & 2186.69 & \pm & 113.37 \\
C16:1 & 122.91 & \pm & 22.26 & 39.32 & \pm & 2.68 & 96.65 & \pm & 12.43 & 102.91 & \pm & 4.26 & 116.98 & \pm & 11.89 \\
C18:1 & 325.12 & \pm & 50.33 & 226.71 & \pm & 25.59 & 272.73 & \pm & 16.77 & 413.02 & \pm & 19.16 & 488.77 & \pm & 43.88 \\
$\sum$ MUFA & 448.03 & \pm & 71.97 & 266.03 & \pm & 26.73 & 369.38 & \pm & 15.95 & 515.92 & \pm & 17.57 & 605.74 & \pm & 46.09 \\
C18:2 & 44.44 & \pm & 9.96 & 10.42 & \pm & 5.48 & 36.59 & \pm & 4.66 & 16.06 & \pm & 0.93 & 97.52 & \pm & 16.11 \\
C18:3 & 31.01 & \pm & 4.38 & 10.38 & \pm & 8.94 & 28.10 & \pm & 4.60 & 49.90 & \pm & 10.39 & 40.44 & \pm & 7.48 \\
$\sum$ PUFA & 75.44 & \pm & 13.89 & 20.79 & \pm & 13.73 & 64.69 & \pm & 8.80 & 65.95 & \pm & 10.98 & 137.96 & \pm & 16.42 \\
C20:4 & 271.02 & \pm & 62.58 & 254.10 & \pm & 50.56 & 260.21 & \pm & 21.41 & 527.89 & \pm & 16.26 & 427.78 & \pm & 86.39 \\
C20:5 & 331.31 & \pm & 109.17 & 252.63 & \pm & 34.40 & 659.80 & \pm & 337.32 & 2074.52 & \pm & 152.02 & 1171.47 & \pm & 242.51 \\
$\sum$ HUFA & 602.33 & \pm & 171.38 & 506.73 & \pm & 74.56 & 920.01 & \pm & 335.24 & 2602.41 & \pm & 158.41 & 1599.24 & \pm & 315.65 \\
$\sum$ FA & 2500.67 & \pm & 451.90 & 2105.43 & \pm & 347.98 & 2611.73 & \pm & 368.52 & 5289.05 & \pm & 228.40 & 4529.64 & \pm & 452.94 \\
\hline
\end{tabular}




\subsection{Carbohydrate Characterization}

Monosaccharides present in the samples were analysed after hydrolysis of the polysaccharides. Our method does not permit to separate the two hexoses, glucose and galactose, so they appear together and the results are showing the total glucose + galactose. These two residues (sum of glucose and galactose) were highly identified in all samples, followed by mannose and xylose (Figure 4).

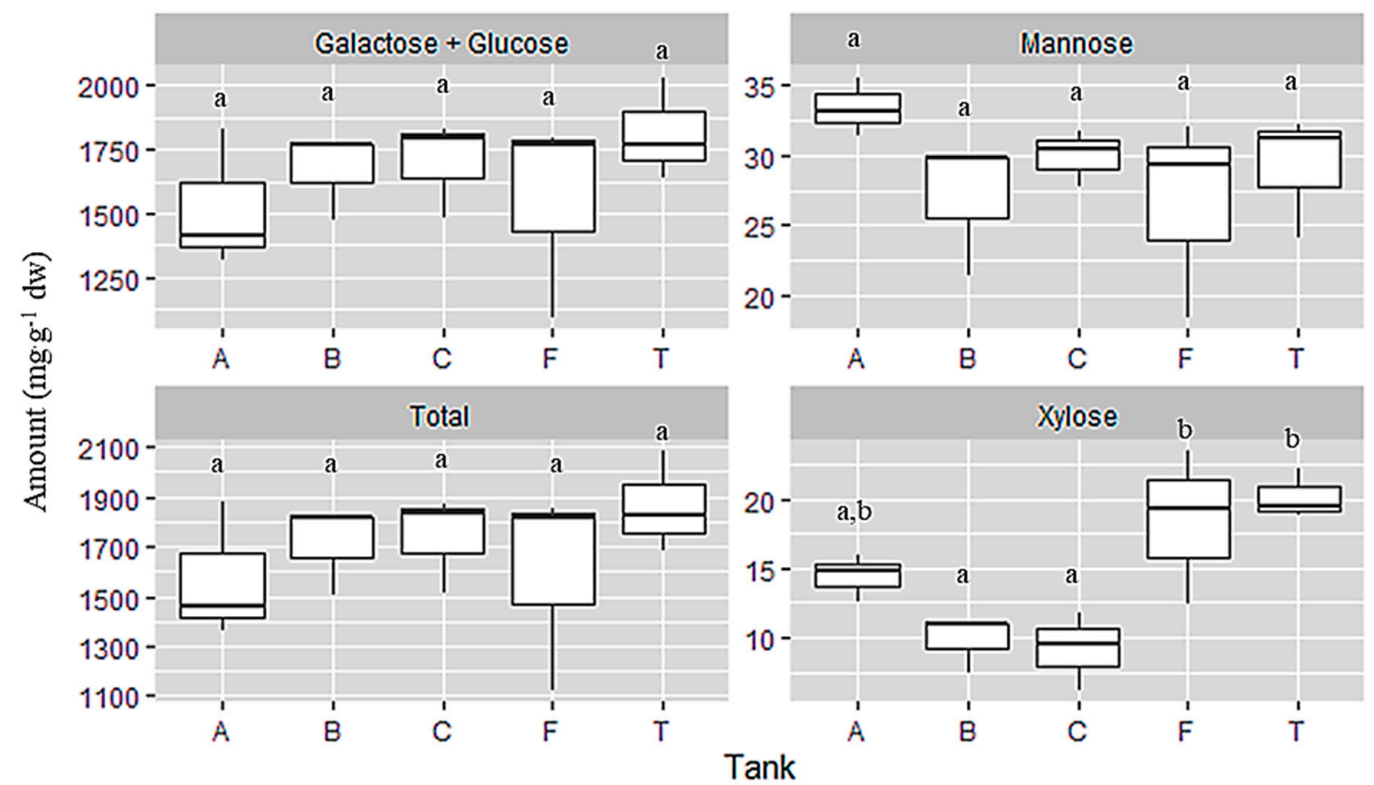

Figure 4. Total monosaccharide composition expressed in $\mathrm{mg} \cdot \mathrm{g}^{-1} \mathrm{dw}$ from samples of $C$. jubata obtained from cultivated in indoor balloons (A, B and C), cultivated in outdoor tank ( $\mathrm{T}$ ) and collected from the field $(F)$. The same upper letters $(a, b)$ mean there are no differences between the treatments (cultivation type). Data as mean value, distribution and variance; $n=3$.

\subsection{Carrageenan Extraction}

In the extraction of the main polysaccharide, all the samples have differences, with the F sample being the best sample assayed and the tank $\mathrm{T}$ cultivation (Outdoor) appearing to be the most stable sample in terms of extraction. In this case, all the indoor cultivations were inserted in only segment (Figure 5).

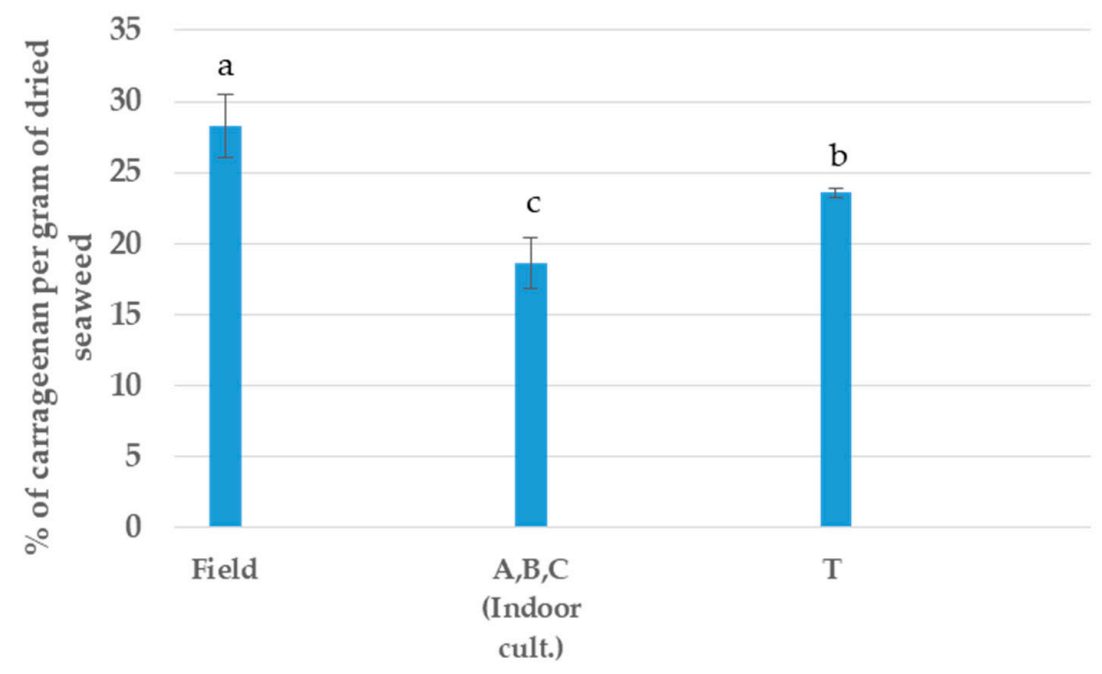

Figure 5. Yield of carrageenan per type of cultivation. ${ }^{a, b, c}$ Equal letters indicate no significant differences at the $p$-value $<0.05$ level. 


\section{Discussion}

C. Jubata indoor cultivation has been studied for a long time by the research team, to obtain more information about this seaweed which has an interesting carrageenan, still with scarce or null information in literature. The cultivation in the lab was proven to be feasible to obtain more information about the performance of this seaweed to be cultivated. However, the inshore cultivation was not possible to be done in triplicated due to the lack of available cultivation tanks, although this first assay demonstrated interesting results in all the assays. This happened mainly due to the cultivation location being near the collection site and the water being considered identical by other researchers that monitor the water quality, in various locations near the collection and cultivation sites. However, the growth was poor when compared to indoor cultivation, this can be explained to the abiotic and biotic factors impact in the semi-controlled cultivation systems, the inshore cultivation system.

Samples collected in the field showed the highest value of fatty acids content since they were outdoors, where the conditions were not under control, due to the constant renewal of the water and the nutrients availability. After field samples, the higher value of fatty acid concentration was followed by tank $T$ which was outside and in a larger proportion of cultivated seaweed. Indeed, the conditions in tank $\mathrm{T}$ were more similar to the field environmental factors.

In the carrageenan yield, the indoor culture was so identical in results that we put together to have more robust analysis. With that analysis, we observed that indoor cultivation presented lower content in carrageenan and more content in FAs than the inshore cultivation.

This is the first time that this species and genus is targeted to be characterized in the fatty acids and carbohydrates and there is a general lack of information about this seaweed, Whose cultivation is more feasible in lower temperatures [28]. However, this species is identical with high rated food consumed red seaweeds in the fatty acids and carbohydrates levels, as Palmaria palmata, Chondrus crispus and Neopyropia tenera [32,33].

The carrageenan extraction yield from all the samples is identical with the work of Pereira [21] in the same location of seaweed collection, however lower when compared to the work of the Zinoun and Cosson [28], that obtained $29 \%$ at the lowest yield of C. jubata, in which was collected in Cap Levy, in France.

Information about carbohydrates content is null in the literature, this being the first study characterizing the carbohydrate profile of this species and in Calliblepharis genus.

\section{Conclusions}

Our results support that seaweed indoor cultivation can help to optimize the overall seaweed cultivation allowing the assess to the ideal growth conditions of C. Jubata. However, this controlled cultivation system had a negative effect in the $C$. Jubata biochemical profile. Thus, the inshore cultivation (partially controlled system) showed more similar results with field samples than with the indoor cultivation system. However, the seaweed inshore cultivation needs to be more assayed to have high growth rate without lowering the biochemical compounds. The procedure of cultivation needs to be optimized to achieve and guarantee high content profiles and thus the best nutritional value.

Further and next plans of the study are to optimize and obtain more information about the aquaculture process of this seaweed species and the full characterization of the nutritional value of wild and cultivated $C$. jubata in parallel with the optimization procedure to guarantee to the stakeholders and farmers the best quality cultivation. The biochemical profile needs to be further analyzed in the quantification and characterization of the uronic acids and sulfate compounds, protein content and amino-acids profile, ash quantification and mineral concentration to have a useful tool to promote the $C$. Jubata cultivation. 
Author Contributions: Conceptualization, G.S.A., J.C. and A.M.M.G.; Seaweed Cultivation, G.S.A., J.C. and T.M.; Fatty Acids and Carbohydrates analysis, A.L. and S.G.-P.; Carrageenan research, G.S.A. and J.C.; writing-original draft preparation, G.S.A., J.C., T.M., A.L. and S.G.-P.; writing-review and editing, J.C., A.M.M.G. and L.P.; supervision, A.M.M.G. and L.P.; project coordination, A.M.M.G.; funding acquisition, A.M.M.G. and L.P. All authors have read and agreed to the published version of the manuscript.

Funding: This work is financed by national funds through FCT - Foundation for Science and Technology, I.P., within the scope of the projects UIDB/04292/2020 - MARE - Marine and Environmental Sciences Centre and UIDP/50017/2020+UIDB/50017/2020 (by FCT/MTCES) granted to CESAM - Centre for Environmental and Marine Studies. This work was financed by the Live Food Production Laboratory (LABPAV) and the Tropical Aquaculture Study Group (GEAQUI) of the Federal Institute of Education, Science and Technology of Ceará-IFCE, Campus Aracati, Ceará, Brazil. João Cotas thanks to the European Regional Development Fund through the Interreg Atlantic Area Program, under the project NASPA (EAPA_451/2016). Adriana Leandro thanks FCT for the financial support provided through the doctoral grant SFRH/BD/143649/2019 funded by National Funds and Community Funds through FSE. Sara García-Poza thanks to the project MENU-Marine Macroalgae: Alternative recipes for a daily nutritional diet (FA_05_2017_011) which co-financed this research, funded by the Blue Fund under Public Notice No. 5-Blue Biotechnology. Ana M. M. Gonçalves acknowledges University of Coimbra for the contract IT057-18-7253.

Conflicts of Interest: The authors declare no conflict of interest.

\section{References}

1. Dawes, C.J. Marine Botany; Dawes, C.J., Ed.; John Wiley \& Sons: New York, NY, USA, 1995; ISBN 978-0-471-19208-4.

2. Arasaki, S.; Arasaki, T. Vegetables from the Sea; Japan Publishing Inc.: Tokyo, Japan, 1983.

3. Wong, K.H.; Cheung, P.C.K. Nutritional evaluation of some subtropical red and green seaweeds. Part I-Proximate composition, amino acid profiles and some physico-chemical properties. Food Chem. 2000, 71, 475-482. [CrossRef]

4. Armisen, R. World-wide use and importance of Gracilaria. J. Appl. Phycol. 1995, 7, 231-243. [CrossRef]

5. Leandro, A.; Pacheco, D.; Cotas, J.; Marques, J.C.; Pereira, L.; Gonçalves, A.M.M. Seaweed's Bioactive Candidate Compounds to Food Industry and Global Food Security. Life 2020, 10, 140. [CrossRef] [PubMed]

6. Pereira, L. Biological and therapeutic properties of the seaweed polysaccharides. Int. Biol. Rev. 2018, 2, 1-50. [CrossRef]

7. Wijesekara, I.; Kim, S.K. Application of Marine Algae Derived Nutraceuticals in the Food Industry. Mar. Algae Extr. Process. Prod. Appl. 2015, 2, 627-638. [CrossRef]

8. De Jesus Raposo, M.F.; De Morais, A.M.B.; De Morais, R.M.S.C. Marine polysaccharides from algae with potential biomedical applications. Mar. Drugs 2015, 13, 2967-3028. [CrossRef] [PubMed]

9. Michalak, I.; Chojnacka, K. Algae as production systems of bioactive compounds. Eng. Life Sci. 2015, 15, 160-176. [CrossRef]

10. De Boer, J.A. A Report on the Fisheries Training and Development Project; FAO Fisheries and Aquaculture: Nassau, Bahamas, 1981.

11. Zhang, H.; Mao, W.; Fang, F.; Li, H.; Sun, H.; Chen, Y.; Qi, X. Chemical characteristics and anticoagulant activities of a sulfated polysaccharide and its fragments from Monostroma latissimum. Carbohydr. Polym. 2008, 71, 428-434. [CrossRef]

12. Farias, W.R.L.; Nazareth, R.A.; Mourão, P.A.S. Dual effects of sulfated D-galactans from the red algae Botryocladia occidentalis preventing thrombosis and inducing platelet aggregation. Thromb. Haemost. 2001, 86, 1540-1546. [CrossRef]

13. Zhou, G.; Sheng, W.; Yao, W.; Wang, C. Effect of low molecular $\lambda$-carrageenan from Chondrus ocellatus on antitumor H-22 activity of 5-Fu. Pharmacol. Res. 2006, 53, 129-134. [CrossRef]

14. Fu, Y.W.; Hou, W.Y.; Yeh, S.T.; Li, C.H.; Chen, J.C. The immunostimulatory effects of hot-water extract of Gelidium amansii via immersion, injection and dietary administrations on white shrimp Litopenaeus vannamei and its resistance against Vibrio alginolyticus. Fish Shellfish Immunol. 2007, 22, 673-685. [CrossRef] [PubMed]

15. Cotas, J.; Leandro, A.; Pacheco, D.; Gonçalves, A.M.M.; Pereira, L. A comprehensive review of the nutraceutical and therapeutic applications of red seaweeds (Rhodophyta). Life 2020, 10, 19. [CrossRef]

16. Ahmed, N.; Thompson, S. The blue dimensions of aquaculture: A global synthesis. Sci. Total Environ. 2019, 652, 851-861. [CrossRef] [PubMed] 
17. Cardozo, K.H.M.; Guaratini, T.; Barros, M.P.; Falcão, V.R.; Tonon, A.P.; Lopes, N.P.; Campos, S.; Torres, M.A.; Souza, A.O.; Colepicolo, P.; et al. Metabolites from algae with economical impact. Comp. Biochem. Physiol. C Toxicol. Pharmacol. 2007, 146, 60-78. [CrossRef] [PubMed]

18. Buschmann, A.H.; Camus, C.; Infante, J.; Neori, A.; Israel, Á.; Hernández-González, M.C.; Pereda, S.V.; Gomez-Pinchetti, J.L.; Golberg, A.; Tadmor-Shalev, N.; et al. Seaweed production: Overview of the global state of exploitation, farming and emerging research activity. Eur. J. Phycol. 2017, 52, 391-406. [CrossRef]

19. García-Poza, S.; Leandro, A.; Cotas, C.; Cotas, J.; Marques, J.C.; Pereira, L.; Gonçalves, A.M.M. The Evolution Road of Seaweed Aquaculture: Cultivation Technologies and the Industry 4.0. Int. J. Environ. Res. Public Health 2020, 17, 6528. [CrossRef]

20. Allan, G.L.; Fielder, D.S.; Fitzsimmons, K.M.; Applebaum, S.L.; Raizada, S. Inland Saline Aquaculture; Woodhead Publishing Limited: Cambridge, UK, 2009; ISBN 9781845693848.

21. Pereira, L. Estudos em macroalgas carragenófitas (Gigartinales, Rhodophyceae) da costa portuguesa-Aspectos ecológicos, bioquímicos e citológicos. Ph.D. Thesis, University of Coimbra, Coimbra, Portugal, 2004.

22. Gaspar, R.; Fonseca, R.; Pereira, L. Guia Ilustrado das Macroalgas da Baía de Buarcos, Figueira da Foz, Portugal; Leonel Pereira: Coimbra, Portugal, 2020.

23. Zinoun, M.; Diouris, M.; Potin, P.; Floc'h, J.Y.; Deslandes, E. Evidence of Sulfohydrolase Activity in the Red Alga Calliblepharis jubata. Bot. Mar. 1997, 40, 49-54. [CrossRef]

24. Jouanneau, D.; Guibet, M.; Boulenguer, P.; Mazoyer, J.; Smietana, M.; Helbert, W. New insights into the structure of hybrid $\mathrm{k}-/ \mu$-carrageenan and its alkaline conversion. Food Hydrocoll. 2010, 24, 452-461. [CrossRef]

25. Deslandes, E.; Bodeau-Bellion, C.; Floc'h, J.Y.; Penot, M. 13C-NMR spectroscopy and chemical analysis of the carrageenans of four red algae (Gigartinales). Plant Physiol. Biochem. 1990, 28, 65-69.

26. Pereira, L.; Critchley, A.T.; Amado, A.M.; Ribeiro-Claro, P.J.A. A comparative analysis of phycocolloids produced by underutilized versus industrially utilized carrageenophytes (Gigartinales, Rhodophyta). J. Appl. Phycol. 2009, 21, 599-605. [CrossRef]

27. Pereira, L. Edible Seaweeds of the World; CRC Press: Boca Raton, FL, USA, 2016; ISBN 9780429154041.

28. Zinoun, M.; Cosson, J. Seasonal variation in growth and carrageenan content of Calliblepharis jubata (Rhodophyceae, Gigartinales) from the Normandy coast, France. J. Appl. Phycol. 1996, 8, 29-34. [CrossRef]

29. Gonçalves, A.M.M.; Pardal, M.Â.; Marques, S.C.; Mendes, S.; Fernández-Gómez, M.J.; Galindo-Villardón, M.P.; Azeiteiro, U.M. Responses of copepoda life-history stages to climatic variability in a southern-European temperate estuary. Zool. Stud. 2012, 51, 321-335.

30. Coimbra, M.A.; Waldron, K.W.; Selvendran, R.R. Isolation and characterisation of cell wall polymers from olive pulp (Olea europaea L.). Carbohydr. Res. 1994, 252, 245-262. [CrossRef]

31. Pereira, L.; van de Velde, F. Portuguese carrageenophytes: Carrageenan composition and geographic distribution of eight species (Gigartinales, Rhodophyta). Carbohydr. Polym. 2011, 84, 614-623. [CrossRef]

32. Pereira, L. A review of the nutrient composition of selected edible seaweeds. In Seaweed: Ecology, Nutrient Composition and Medicinal Uses; Pomin, V.H., Ed.; Nova Science Publishers, Inc.: Hauppauge, NY, USA, 2011; pp. 15-47, ISBN 978-1-61470-878-0.

33. Schmid, M.; Kraft, L.G.K.; van der Loos, L.M.; Kraft, G.T.; Virtue, P.; Nichols, P.D.; Hurd, C.L. Southern Australian seaweeds: A promising resource for omega-3 fatty acids. Food Chem. 2018, 265, 70-77. [CrossRef]

Publisher's Note: MDPI stays neutral with regard to jurisdictional claims in published maps and institutional affiliations.

(C) 2020 by the authors. Licensee MDPI, Basel, Switzerland. This article is an open access article distributed under the terms and conditions of the Creative Commons Attribution (CC BY) license (http://creativecommons.org/licenses/by/4.0/). 